\title{
Body Composition and Dietary Intake of Elite Cross-country Skiers Members of the Greek National Team
}

Sousana K. Papadopoulou ${ }^{1}$; Anna Gouvianaki ${ }^{1}$; Maria G. Grammatikopoulou ${ }^{1}$; Zoi Maraki ${ }^{1}$; Ioannis G. Pagkalos ${ }^{2}$; Nikolaos Malliaropoulos ${ }^{3}$, MD, PhD; Maria N. Hassapidou ${ }^{1}$; Nicola Maffulli*4 ${ }^{4}$, MD, PhD, FRCS(Orth)

Authors' Affiliation:

1. Department of Nutrition \& Dietetics, Alexander Technological Educational Institute, Thessaloniki, Greece

2. Department of Mathematical, Physical and Computational Sciences, Faculty of Engineering, Aristotle University of Thessaloniki, Greece

3. National Track \& Field Centre, Sports Injury Clinic, Sports Medicine Clinic of S.E.G.A.S., Thessaloniki, Greece

4. Centre of Sports and Exercise Medicine, Barts and The London School of Medicine and Dentistry, Mile End Hospital, London, UK

* Corresponding Author;

Address: Centre for Sports and Exercise Medicine, Mile End Hospital, 275 Bancroft Road,

London E1 4DG, UK

E-mail: n.maffulli@qmul.ac.uk

Received: $\operatorname{Apr} 29,2012$

Accepted: Jul 20, 2012

Key Words: Athletes; Body Fat; Cross-country Skiing; Nutrients; Diet

\begin{abstract}
Purpose: To assess the anthropometric characteristics and dietary intake of the Greek national cross-country skiing team.
\end{abstract}

Methods: Thirty-three athletes (10 females aged $20 \pm 5$ years; 23 males aged $20 \pm$ 6 years old) participated in the study. All athletes were members of the Greek national ski team, and they had been selected to take part in the Winter Olympics, World Ski Championships, European Ski Championships or other international events, according to their performance. Body composition was estimated by bioelectrical impedance (BIA) and skinfold thickness. The athletes recorded their physical activity and dietary intake for 3 training days, and on a competition day.

Results: The female skiers had $14.2 \pm 1.9 \%$ body fat, the men $11.0 \pm 1.5 \%$ body fat. Female athletes consumed a diet of $1988 \pm 319$ Kcal during training days and $2011 \pm 330$ Kcal during competition days. Male athletes consumed $2255 \pm 790$ Kcal and $2125 \pm 639 \mathrm{Kcal}$ respectively. These values are below those recommended for highly active people. During the training period, carbohydrate, fat and protein contributed to $44.5 \pm 7.1 \%, 39.2 \pm 5.3 \%$ and $16.1 \pm 3.7 \%$ of the total energy intake (EI) respectively for the males, and to $52.8 \pm 5.6 \%, 33.0 \pm 3.7 \%$ and $14.3 \pm 2.5 \%$ of the EI of the women. Between training and competition days, men demonstrated an increased carbohydrate and reduced fat consumption when competing $(P<0.001$ for both). Women, on the other hand, consumed more carbohydrate and less protein during competition days $(P<0.05$ for both). Protein intake was within the recommended range for both males and females, but fat exceeded the recommended values and was consumed at the expense of carbohydrate. Vitamins $\mathrm{B}_{12}, \mathrm{D}, \mathrm{E}$ and $\mathrm{K}$, biotin, folate, $\mathrm{Ca}, \mathrm{Mg}, \mathrm{K}$, I were inadequately consumed (below the RDA) by both women and men, while the women also exhibited inadequate intakes of iron and the men of manganese.

Conclusions: The inadequate energy and nutrient intake in the Greek national cross-country ski team could put the athletes at risk of nutritional deficiencies, and possibly compromise their athletic performance.

Asian Journal of Sports Medicine, Volume 3 (Number 4), December 2012, Pages: 257-266

\section{INTRODUCTION}

Cross-country skiing is an endurance sport popular in Northern Europe, Canada and the United States of America ${ }^{[1]}$. Individual races last 12 to 90 minutes for female athletes, and 22 to 140 minutes for the men, involving downhill, uphill and level skiing ${ }^{[2]}$. In contrast to distance running and long-distance cycling, cross-country skiing uses both upper and lower body muscles ${ }^{[3,4]}$. Athletes spend many years building their aerobic performance capabilities ${ }^{[5]}$, and this explains why elite cross-country skiers demonstrate increased training age compared to athletes from other endurance sports ${ }^{[2]}$. An optimum sport-specific body size and body composition is required in order to maximise athletic performance, elite cross-country skiers are as 
lean as distance runners ${ }^{[6]}$. However, within the sport itself variations in physiology have been noted ${ }^{[6]}$ being attributed mainly to the body mass of the athletes, with the heavy skiers being faster in all types of terrain, except for the steep uphills ${ }^{[7]}$, and the light skiers having an advantage on steep uphill courses.

Given the high exercise demands, proper nutrition is important for performance and endurance in crosscountry skiing. Replacing or regenerating hormonal depletion, nervous functions, energy reserves, dehydration and electrolytes transfer, can be accomplished through adequate nutrition ${ }^{[8]}$.

The sport is mainly dependent on carbohydrates as the main energy source ${ }^{[9]}$, and a high-carbohydrate diet $(7-10 \mathrm{~g} / \mathrm{kg}$ body mass (BM)) has therefore been recommended ${ }^{[2]}$. Proteins have a low contribution to the energy production (5\%), and the daily intake of 1.2$1.7 \mathrm{~g} / \mathrm{kg}$ of $\mathrm{BM}$ has been proposed as adequate ${ }^{[10]}$. Recommendations regarding the consumption of fat suggest an intake of $20-35 \%$ of the total energy intake ${ }^{[10]}$, but athletes tend to overconsume fat following a medium to high fat diet ${ }^{[11,12]}$. When nutrient intake is not adequate, cross-country skiers exhibit lower antioxidant enzyme activity and cortisol levels ${ }^{[13]}$, increased cell damage which may lead to impaired performance and injuries ${ }^{[13]}$. Despite the importance of nutrition, limited data are available on the energy and nutrient intake of elite athletes, especially in Greece ${ }^{[14-}$ ${ }^{18]}$. There is lack of data regarding anthropometrics and nutrition status of elite cross-country skiers.

Cross-country skiing is traditionally practiced in Northern Europe ${ }^{[1]}$, where the climate is favorable. In Greece, the first recorded cross-country skiing competition took place during the 1968 Winter Olympics. Since then, the sport became popular throughout the country, and several athletes have achieved awards in international competitions. Considering the lack of dietary data regarding crosscountry skiers and the lack of tradition in the sport in Greece, we designed the present study to record energy and nutrient intake of elite Greek cross-country skiers and their nutritional strategies. Thus the present study aimed to assess the anthropometric characteristics and dietary intake of the Greek national cross-country skiing team, to estimate adequacy in energy intake, macro and micro nutrients and in food group equivalents and investigate differences in nutritional status according to training period and according to gender.

\section{METHODS AND SUBJECTS}

\section{Sample:}

Thirty-three athletes (10 females aged $20 \pm 5$ years, and 23 males aged $20 \pm 6$ years; $7 \pm 3$ training years for women, and $8 \pm 4$ training years for men) participated in the study. Athletes belonged to 4 different ski clubs in Northern Greece, where the sport is better organised.

All the participants in the present study were members of the national team. They trained on a defined schedule, were often abroad, and participated in international competitions including the Winter Olympics, World Ski Championships, European Ski Championships, depending on their performance records. Thus, the sample selection was not random, and we examined the best Greek cross-country skiers. During data collection, the participants were all freeliving.

All subjects and their coaches were informed of the nature and purpose of the study and gave their written consent before participating. The procedures described in the present investigation were approved by the Research Committee of the Alexander Technological Educational Institute, in Thessaloniki, Greece.

\section{Anthropometric Measurements:}

All anthropometric measurements were taken in the morning (08:00-11:00 hours), indoors, from the same experienced dietician and physical education teacher, to avoid inter-examiner variability. Anthropometric measurements took place one day before the activity diary record. Room temperature was regulated between $27-35^{\circ} \mathrm{C}$ at less than $50 \%$ humidity, to help subjects relax and avoid low-temperature-induced muscle stiffness, and they were dressed lightly.

Height was measured to the nearest $0.5 \mathrm{~cm}$ with a stadiometer, with an accuracy of $0.5 \mathrm{~cm}$ (SECA 220, Seca Corporation, Columbia, USA). Body mass was measured using a regular calibrated digital scale with an accuracy of $\pm 100 \mathrm{~g}$ (Seca 707, Seca Corporation, 
Columbia, USA). Body mass index (BMI) was defined as the individual's body mass divided by the square of height $\left(\mathrm{kg} / \mathrm{m}^{2}\right)$.

Waist circumference (WC) was measured midway between the top of the iliac crest and the bottom of the rib cage, at the end of gentle expiration. Hip circumference (HC) was measured over the great trochanters. Circumferences were measured with a tape to the nearest $0.1 \mathrm{~cm}$ over the naked skin. The Waist to Hip ratio (WHR) was calculated as waist circumference $(\mathrm{cm}) /$ hip circumference $(\mathrm{cm})$.

Body fat was estimated with two methods, the skinfold thickness method and bioelectrical impendence analysis (BIA). Skinfolds were taken from the right side of the body at seven sites: triceps, subscapular, suprailiac, chest, abdomen, thigh and midaxillary using a Harpenden skinfold caliper (British Indicators Ltd, London). Skinfold measurements were carried out in duplicate and the mean recorded value was used ${ }^{[19]}$. The Jackson and Pollock equation ${ }^{[20]}$ was used for male skiers and the Jackson, Pollock and Ward ${ }^{[21]}$ equation for the female skiers. Body density was converted to body fat percentage using the Siri equations ${ }^{[22]}$.

A Maltron 907 bioelectrical impendence analyser (Maltron, Rayleigh, Essex, UK) was used for the BIA. Subjects were advised to abstain from exercising, eating or drinking for at least 4 hours prior to the analysis. Participants urinated $30 \mathrm{~min}$ before each measurement. In the women, measurements were taken in the week after the end of their menstrual cycle, to avoid premenstrual water retention. Subjects lay supine with legs and arms slightly abducted. The electrodes were placed on the right hand (one just proximal to the third metacarpophalangeal joint, and one on the wrist between the distal prominence of the radius and ulna) and right foot (one proximal to the third metatarsophalangeal joint and one on the ankle between the medial and the lateral malleoli).

\section{Physical activity:}

All athletes completed a physical activity record for three consecutive training days and for a competition day. The competition consisted of a $10 \mathrm{~km}$ race for athletes younger than 18 years old, or a $15 \mathrm{~km}$ race for adult athletes. Training days included roller skiing, jogging, skiing and weight-lifting. The energy cost for each activity has been estimated using the revised tables by Ainsworth et al ${ }^{[23]}$. The RMR value for every skier was multiplied by the average metabolic value, whereas resting metabolism was estimated using the revised Harris \& Benedict equations by Mifflin et al ${ }^{[24]}$.

\section{Dietary intake:}

All subjects recorded their dietary intake for three consecutive training days, as well as for a competition day ${ }^{[25]}$. The time period between training and competition days' measurements was three months.

The days of physical activity and dietary intake were the same. Verbal and written instructions on how to complete their food diaries were given by a state registered dietitian. The use of food models facilitated the athletes to estimate the quantity of food consumed ${ }^{[16]}$. Food intake was analysed for micronutrients using the Food Processor Nutrition Program (version 7.4, 1997, ESHA Research Salem, Oregon). Intake of micronutrients was expressed as a percentage of the Recommended Dietary Allowance (RDA) ${ }^{[26]}$ to estimate the adequacy of micronutrient intake. Dietary intake was also divided into food group equivalents, in accordance to USDA ${ }^{[27]}$.

\section{Statistical analyses:}

Independent samples t-tests were used for comparison between the two sexes. Paired samples $t$-tests were used to compare training and competition days for the total of the subjects. Pearson correlation was performed to study the association between body fat estimated with the skinfold thickness method and using BIA. Data were checked for normality distribution. Results are presented as mean \pm standard deviation. The level of significance was set at $P<0.05$.

\section{RESULTS}

\section{Anthropometry:}

The anthropometric characteristics of the subjects, according to sex, are presented in Table 1 . The mean body mass of the athletes was $64.5 \pm 10.6 \mathrm{~kg}$, and their 
Table 1: Means and standard deviations of anthropometric characteristics of female and male cross country skiers

\begin{tabular}{|c|c|c|c|c|}
\hline \multicolumn{2}{|l|}{ Parameter } & $\begin{array}{c}\text { Women } \\
(n=10)\end{array}$ & $\begin{array}{l}\text { Men } \\
(\mathbf{n}=\mathbf{2 3})\end{array}$ & $P$ value \\
\hline & Weight $(\mathrm{kg})$ & $54.2(6.2)+\dagger$ & $69.0(9.0)$ & $<0.001$ \\
\hline & Height $(\mathrm{cm})$ & $164.7(6.2) \dagger$ & $175.3(6.3)$ & $<0.05$ \\
\hline & Body Mass Index $\left(\mathrm{Kg} / \mathrm{m}^{2}\right)$ & $20.0(1.4) \dagger$ & $22.4(2.2)$ & $<0.05$ \\
\hline & Waist-to-hip ratio & $0.71(0.03) \dagger \dagger$ & $0.78(0.03)$ & $<0.001$ \\
\hline & $\%$ body fat (calliper) & $14.6(3.0) \dagger \dagger$ & $7.5(2.8)$ & $<0.001$ \\
\hline & $\%$ body fat (BIA) & $14.2(1.9) \dagger \dagger$ & $11.0(1.5)$ & $<0.001$ \\
\hline & Fat body mass (Kg) (BIA) & $7.8(1.8)$ & $7.7(1.6)$ & NS \\
\hline & Lean body mass $(\mathrm{Kg})(\mathrm{BIA})$ & $46.4(4.6) \dagger \dagger$ & $61.3(7.9)$ & $<0.001$ \\
\hline & \% Body water (BIA) & $62.8(1.4)+\dagger$ & $65.2(1.3)$ & $<0.001$ \\
\hline & Body water $(\mathrm{Kg})$ (BIA) & $34.0(3.4)+\dagger$ & $45.1(5.8)$ & $<0.001$ \\
\hline \multirow{7}{*}{ Skinfolds (mm) } & Chest & $5.1(1.4)$ & $5.0(1.2)$ & NS \\
\hline & Midauxilliary & $6.5(2.1)$ & $6.2(2.1)$ & NS \\
\hline & Triceps & $10.5(2.5) \dagger \dagger$ & $6.7(2.1)$ & $<0.001$ \\
\hline & Subscapullar & $10.1(3.4)$ & $10.0(2.2)$ & NS \\
\hline & Abdomen & $11.2(3.8)$ & $10.8(5.4)$ & NS \\
\hline & Suprailliac & $10.2(4.1)$ & $9.1(4.1)$ & NS \\
\hline & Thigh & $20.3(3.3) \dagger \dagger$ & $12.8(3.3)$ & $<0.001$ \\
\hline \multirow{6}{*}{ Circumferences (cm) } & Wrist & $14.4(0.6) \dagger \dagger$ & 16. (1.1) & $<0.001$ \\
\hline & Waist & $66.1(3.4)+\dagger$ & $74.9(5.2)$ & $<0.001$ \\
\hline & Hip & $93.1(5.3)$ & $96.2(5.1)$ & NS \\
\hline & Chest & $85.3(3.6) \dagger$ & $90.8(7.2)$ & $<0.05$ \\
\hline & Shoulders & $97.6(4.8) \dagger \dagger$ & $111.6(7.2)$ & $<0.001$ \\
\hline & Arm & $24.2(1.5) \dagger \dagger$ & $28.7(3.3)$ & $<0.001$ \\
\hline \multirow{2}{*}{ Widths (mm) } & Elbow & $62.6(3.0) \dagger \dagger$ & $73.0(4.5)$ & $<0.001$ \\
\hline & Knee & $98.7(5.4)$ & $101.4(5.6)$ & NS \\
\hline
\end{tabular}

NS: Non-significant

their mean height was $172.1 \pm 7.8 \mathrm{~cm}$. The average BMI of the cross-country skiers was $21.7 \pm 2.3 \mathrm{~kg} / \mathrm{m}^{2}$, with the BMI of the male athletes being $22.4 \pm 2.2 \mathrm{~kg} / \mathrm{m}^{2}$, and that of the female athletes $20.0 \pm 1.4 \mathrm{~kg} / \mathrm{m}^{2}$. As expected, male athletes were taller, heavier and had higher values in BMI and WHR in comparison to the females, while they demonstrated lower values in body fat as estimated by both methods (BIA and skinfold thickness). There was evidence of a statistically significant association $(\mathrm{r}=0.719)$ between body fat estimated by means of skinfold thickness and body fat measured by BIA.

\section{Energy intake and macronutrient intake:}

Energy expenditure, energy intake and macronutrient intake according to sex are shown in Table 2. Males had significantly higher energy expenditure both during training and competition days compared to females (independent samples $t$-test; $P<0.05$ ). However, their energy intakes were lower compared to their estimated energy needs for both males and females. During the training period, carbohydrate, fat and protein contributed to $44.5 \pm 7.1 \%, 39.2 \pm 5.3 \%$ and $16.1 \pm 3.7 \%$ of the total energy intake (EI) respectively for the males, and to $52.8 \pm 5.6 \%, 33.0 \pm 3.7 \%$ and $14.3 \pm 2.5 \%$ of the EI of the women. Carbohydrate consumption expressed per $\mathrm{g} / \mathrm{kg}$ of $\mathrm{BW}$, both in training and competition days, was lower in the men compared to the women $(P<0.05)$. The men appeared to consume significantly more fat, expressed as $\% \mathrm{EI}$, compared to the women while training. Between training and competition days, men demonstrated an increased carbohydrate and reduced fat consumption when competing $(P<0.001$ for both). Women, on the other hand, consumed more carbohydrate and less protein during competition days $(P<0.05$ for both). Alcohol consumption was low among the participants of this study, at less than two units per alcohol per week in both male and female skiers.

\section{Consumption of food groups:}

Consumption of food groups' equivalents are presented 
Table 2: Energy expenditure, energy intake and macronutrient intake of female and male cross country skiers, during training and competition days

\begin{tabular}{|c|c|c|c|c|}
\hline \multirow{2}{*}{ Parameter } & \multicolumn{2}{|c|}{ Women $(n=10)$} & \multicolumn{2}{|c|}{ Men $(n=23)$} \\
\hline & Training & Competition & Training & Competition \\
\hline Energy expenditure (Kcal/day) & $2580(307) \dagger$ & $2466(327) \dagger$ & $3095(582)$ & $2911(508)$ \\
\hline Energy intake (Kcal/day) & $1988(319)$ & $2011(330)$ & $2255(790)$ & $2125(639)$ \\
\hline Protein (g) & $72.6(18.5)$ & $62.7(16.5)$ & $92.5(39.9)$ & $79.7(28.5)$ \\
\hline Protein (g/kg Body Weight) & $1.4(0.4)$ & $1.2(0.3)$ & $1.3(0.5)$ & $1.2(0.4)$ \\
\hline Protein (\%Energy Intake) & $14.3(2.5)^{*}$ & $12.4(2.7)$ & $16.1(3.7)$ & $15.3(4.7)$ \\
\hline Carbohydrate (g) & $266.7(43.8)$ & $293.8(59.3)$ & $254.5(108.7)$ & $290.1(104.2)$ \\
\hline Carbohydrate (g/kg Body Weight) & $4.9(1.1) \dagger$ & $5.5(1.3) \dagger$ & $3.7(1.5)$ & $4.2(1.4)$ \\
\hline Carbohydrate (\%Energy Intake) & $52.8(5.6) \dagger$ & $57.7(7.7)$ & $44.5(7.1)^{* *}$ & $53.7(9.0)$ \\
\hline Fat (g) & $74.6(15.8) \dagger$ & $68.1(17.4)$ & $98.7(32.9)^{* *}$ & $72.6(29.6)$ \\
\hline Fat (g/kg Body Weight) & $1.4(0.4)$ & $1.3(0.3)$ & $1.4(0.5)$ & $1.1(0.5)$ \\
\hline Fat (\%Energy Intake) & $33.0(3.7) \dagger$ & $29.9(5.7)$ & $39.2(5.3)^{* *}$ & $30.3(8.1)$ \\
\hline Saturated fat (g) & $25.3(9.9)$ & $23.9(9.0)$ & $33.6(12.3)$ & $24.2(12.3)$ \\
\hline Alcohol (\%Energy Intake) & $0.0(0.0)$ & $0.0(0.0)$ & $0.2(0.6)$ & $0.7(3.0)$ \\
\hline Fibre (g) & $17.7(3.9)$ & $13.2(4.4)$ & $16.6(7.5)$ & $13.6(6.9)$ \\
\hline Cholesterol (mg) & $159.9(73.7)$ & $129.7(63.8)$ & $239.9(123.6)$ & $183.8(86.3)$ \\
\hline
\end{tabular}

in Table 3.

Women consumed more fruit compared to men $(P<0.05)$. When training and competition days were compared, Greek male cross country skiers had a reduced milk products intake $(P<0.001)$, and female cross country skiers an increased bread and cereals consumption $(P<0.05)$ when competing.

\section{Micronutrient intake:}

Micronutrient intake is presented in Table 4. Female cross country skiers demonstrated a significantly higher dietary intake of vitamin $\mathrm{C}(P<0.05)$, when training and a reduced dietary intake of iron compared to the male cross country skiers, noted both during training and competition days, $(P<0.001$ for both). Between training and competition days, the male cross country skiers exhibited higher intakes in vitamin $\mathrm{A}$ $(P<0.001)$, vitamin $\mathrm{B}_{2}(P<0.05)$, vitamin $\mathrm{B}_{12}(P<0.05)$, biotin $(P<0.05)$, vitamin $\mathrm{K} \quad(\mathrm{p}<0.05)$, vitamin $\mathrm{E}$ $(P<0.001)$, vitamin D $(P<0.001)$, calcium $(P<0.001)$ and lower intake of vitamin $\mathrm{B}_{1}(P<0.05)$ during training days. Female cross country skiers, on the other hand, demonstrated higher dietary intake of calcium and vitamins $\mathrm{B}_{2}, \mathrm{~B}_{12}, \mathrm{~K}, \mathrm{E}$, and lower selenium and folate consumption $(P<0.05$ for all $)$ when training.

Finally, table 5 shows the intake of supplementation by the athletes.

Table 3: Food groups servings intake during training and competition days in female and male cross country skiers

\begin{tabular}{lcccc} 
& \multicolumn{2}{c}{ Women $(\mathbf{n}=\mathbf{1 0})$} & \multicolumn{2}{c}{ Men $(\mathbf{n}=\mathbf{2 3})$} \\
training & Competition & training & Competition \\
\hline Bread and cereal (servings/day) & $6.0(1.9)^{*}$ & $8.5(3.0)$ & $8.3(4.1)$ & $8.9(3.8)$ \\
Vegetables (servings/day) & $3.7(1.6)$ & $3.1(2.4)$ & $4.5(2.2)$ & $3.9(2.4)$ \\
Fruits (servings/day) & $6.6(4.3) \dagger$ & $5.9(5.4)$ & $3.5(2.6)$ & $3.7(4.8)$ \\
Meat and products (servings/day) & $2.2(0.1)$ & $2.4(1.2)$ & $3.2(2.0)$ & $2.9(1.4)$ \\
Milk (servings/day) & $3.3(1.4)$ & $3.0(1.0)$ & $4.1(2.1)^{* *}$ & $2.5(1.8)$ \\
Fat (servings/day) & $12.1(6.0)$ & $12.7(5.6)$ & $12.1(5.8)$ & $11.1(5.5)$
\end{tabular}

${ }^{\dagger}$ Significant difference compared to the men $(P<0.05)$

* Significant difference compared to competition days $(P<0.05)$

** Significant difference compared to competition days $(P<0.001)$ 
Table 4: \% DRI intake of vitamins and minerals during training and competition days in female and male cross country skiers

\begin{tabular}{|c|c|c|c|c|}
\hline & \multicolumn{2}{|c|}{ Women $(n=10)$} & \multicolumn{2}{|c|}{ Men $(n=23)$} \\
\hline & training & Competition & training & competition \\
\hline Vit A & $122.1(43.3)$ & $84.3(37.9)$ & $101.9(50.4)^{* *}$ & $62.7(30.3)$ \\
\hline Vit $B_{1}$ & $155.8(34.4)$ & $177.7(40.0)$ & $147.4(59.8)^{*}$ & $176(79.5)$ \\
\hline Vit $\mathbf{B}_{2}$ & $209.7(49.6)^{*}$ & $171.8(25.5)$ & $198.1(96.7)^{*}$ & $165.7(65.7)$ \\
\hline Vit $B_{3}$ & $139.6(30.1)$ & $143.5(37.5)$ & $145.2(76)$ & $160.6(51.5)$ \\
\hline Vit $B_{6}$ & $146.8(50.9)$ & $122.2(41.8) \dagger$ & $146.6(84.1)$ & $163.2(76.7)$ \\
\hline Vit $B_{12}$ & $138.4(54.3)^{*}$ & $89.7(45.4)$ & $204.2(148.6)^{*}$ & $136.5(72.8)$ \\
\hline Biotin & $78.5(19.4)$ & $78.1(29.2)$ & $83.2(44.0)^{*}$ & $66.7(49.4)$ \\
\hline Vit C & $413.1(300.5) \dagger$ & $528.8(486.6)$ & $252.5(153.1)$ & $292.2(349.1)$ \\
\hline Vit D & $78.8(45.9)$ & $44.5(38.8)$ & $106.6(86.6)^{*}$ & $61.2(50.1)$ \\
\hline Vit E & $77.7(15.6)^{*}$ & $48.6(14.6)$ & $91.6(45.1)^{*}$ & $54.6(30.8)$ \\
\hline Vit $\mathrm{K}$ & $36.5(28.6)^{*}$ & $16.10(11.3)$ & $31.6(29.0)^{*}$ & $16.0(12.5)$ \\
\hline Folate & $82(22.9)^{*}$ & $111.1(28.8)$ & $90.6(37.9)$ & $91.5(42.8)$ \\
\hline Pantothenic Acid & $113.3(35.5)$ & $98.1(40.4)$ & $130.6(76.4)$ & $109.4(60.8)$ \\
\hline Calcium (Ca) & $85.5(27.4)^{*}$ & $68.1(22.6)$ & $103.4(57.3)^{* *}$ & $65.6(34.2)$ \\
\hline Iron (Fe) & $73.1(15.5) \dagger \dagger$ & $67.3(19.6) \dagger \dagger$ & $138.0(71.3)$ & $140.0(60.0)$ \\
\hline Magnesium (Mg) & $75.4(12.9)$ & $68.1(16.5)$ & $75.0(54.2)$ & $61.3(19.7)$ \\
\hline Phosphor (P) & $121.5(32.7)$ & $105.4(37.2)$ & $147.4(93.6)$ & $123.9(56.6)$ \\
\hline Potassium (K) & $75.4(19.9)$ & $62.5(32.1)$ & $71.8(33.5)$ & $66.0(37.0)$ \\
\hline Sodium (Na) & $132.8(56.8)$ & $127.9(61.7)$ & $162.2(72.2)$ & $135.8(71.8)$ \\
\hline Iodine (I) & $61.1(36.8)$ & $35.5(34.6)$ & $78.9(66.9)$ & $41.1(37.7)$ \\
\hline Manganese (Mn) & $102.1(22.2)$ & $107.0(39.7)$ & $88.8(49.1)$ & $86.9(39.7)$ \\
\hline Selenium (Se) & $121.8(34.3)^{*}$ & $154.0(51.7)$ & $166.9(77.6)$ & $177.6(82.2)$ \\
\hline
\end{tabular}

\section{DISCUSSION}

\section{Anthropometry:}

In terms of physique and body composition, our female cross country skiers demonstrated lower values in all anthropometric indices measured, except for the triceps and thigh skinfolds and their total body fat content compared to the men. Compared to athletes from different sports, the male cross country skiers in the present study exhibited lower BMI compared to Spanish mountaineering skiers ${ }^{[13]}$, as well as to Caucasian Ironman triathlon athletes ${ }^{[28-30]}$, but similar BMI to ultra endurance runners ${ }^{[31]}$. Greek female skiers had lower BMI and percent body fat values than

Table 5: Intake of supplements by female and male cross country skiers

\begin{tabular}{lcc} 
& Women $(\mathbf{n}=\mathbf{1 0})$ & Men $(\mathbf{n = 2 3})$ \\
\hline Use of supplements (\%¥) & 60.0 & 56.5 \\
Sport drinks (\%¥) & 50.0 & 52.2 \\
Proteins (\%¥) & 10.0 & 4.3 \\
Creatine (\%¥) & 10.0 & 4.3 \\
Glutamine (\%¥) & 20.0 & 8.7 \\
Carnitine (\%¥) & 10.0 & 0.0 \\
Other amino acids (\%¥) & 0.0 & 21.7 \\
Vitamins (\%¥) & 20.0 & 39.1 \\
Iron (\%¥) & 30.0 & 34.8 \\
Calcium (\%¥) & 0.0 & 13.0 \\
Other metals & 0.0 & 8.7 \\
Caffeine (\%¥) & 10.0 & 8.7 \\
$¥:$ Yes & &
\end{tabular}


female Ironman triathletes ${ }^{[32]}$.

In comparison to other sports using upper body power, the athletes participating in the present study demonstrated lower BMI compared to the Norwegian International rowers ${ }^{[33]}$, as well as to Greek sailboarders ${ }^{[16]}$. Average \% body fat was within optimum range, similar to that reported for other endurance athletes ${ }^{[33]}$, including the Italian sub-elite national skiers ${ }^{[34]}$. Greek skiers demonstrated a lower mean body fat value compared to endurance athletes from other countries ${ }^{[13,28-31,35]}$ as well as to Greek endurance athletes from other sports ${ }^{[16,36-38]}$. The athletes who have lower body fat content are elite long distance runners [39] and elite rowers [33]. This phenomenon could be explained either by the high fat diet content adopted by the present participants or by a possibly lower training load compared to the long distance runners and rowers.

The two methods used for assessing body composition (skinfold thickness and BIA) were highly correlated $\quad(\mathrm{r}=0.719, \quad \mathrm{p}<0.001)$. However, BIA systematically showed higher values for body fat percentage, a finding in accordance to a previous study ${ }^{[40]}$. Both methods are likely to estimate body fat with a $3-4 \%$ error $^{[10]}$.

\section{Energy intake and energy balance:}

In the present study, the athletes had markedly lower energy intake compared to their estimated energy expenditure, suggesting a negative energy balance. Similarly, a negative energy balance has been demonstrated in Spanish mountaineering skiers ${ }^{[13]}$. It is widespread among athletes to underreport their energy intake and it should be taken into account when interpreting dietary assessment results ${ }^{[41]}$. According to Nogueira and Da Costa, an implementation of reference intakes (DRIs) for assessing sufficiency of dietary intake would fill the gap between reliable information about food intake and dietary adequacy of athletes and it would be also helpful the use of an independent and external marker for allowing comparison ${ }^{[42]}$.

Cross-country skiing involves strenuous ultraendurance exercise, which takes place in extreme environmental conditions, such as high altitude and cold temperature. A $5-30 \mathrm{~km}$ race is skied at $90-95 \%$ of an athlete's $\mathrm{VO}_{2} \max$, and the energy yield of a $15 \mathrm{~km}$ race is estimated around 950-1200 Kcal for the men ${ }^{[9]}$. Women use $30 \%$ less energy compared to men, given their lower body mass, producing lower friction between the ski and the snow, and a lower $\mathrm{VO}_{2} \max { }^{[7]}$. Nevertheless, skiers should be encouraged to increase their total energy intake according to the demands of their sport to ensure adequate energy stores for optimum performance during competition. Athletes should eat by discipline and beyond their appetite to consume enough energy to compensate for their needs [43].

\section{Macronutrient intake:}

The most important dietary factor affecting muscle glycogen recovery and storage is the adequate consumption of carbohydrates. In this study, the average daily carbohydrate intake was $4.1 \pm 1.5 \mathrm{~g} / \mathrm{kg}$ of $\mathrm{BM}$ during training and $4.6 \pm 1.5 \mathrm{~g} / \mathrm{kg}$ of BM during competition days. Similar carbohydrate intakes during competition days have been reported by mountaineering skiers ${ }^{[13]}$. These figures are much lower than the current carbohydrate recommendation for athletes $(6-10 \mathrm{~g} / \mathrm{kg} \text { of } \mathrm{BM})^{[10]}$, which could result in lower glycogen stores over time in the athletes involved in the present study ${ }^{[43]}$. Carbohydrates are also inversely related to the rate of protein catabolism during exercise ${ }^{[44]}$. Female endurance athletes are less likely to achieve the recommended carbohydrate intake given frequent restriction of total energy intake to maintain low levels of body fat.

The fat intake of female skiers was $33.0 \pm 3.7 \%$ of their EI when training and 29.9土5.7\% EI when competing, while males consumed a more fat-dense diet. An even higher fat consumption has been exhibited by mountaineering skiers during competition days. Skiers with low fat consumption had increased evidence of cell damage. Therefore, the high-fat diet of the majority of skiers might actually be beneficial in sparing structural lipids of the cell membrane and acting against cell disruption ${ }^{[13]}$.

Regarding protein intake, the athletes in the present study exhibited an intake in agreement with the recommendations for endurance athletes, ranging from $1.3 \mathrm{~g} / \mathrm{kg}$ of $\mathrm{BM}$ during training to $1.2 \mathrm{~g} / \mathrm{kg}$ of $\mathrm{BM}$ during competition days ${ }^{[10]}$. 


\section{Consumption of food groups:}

Female cross country skiers have adopted a diet low in grains and vegetables during competition days, and a diet low in meat, grains and vegetables during training days. The low meat intake might partly explain the inadequate dietary iron exhibited by the women athletes. The dietary pattern of male cross country skiers was similar between training a competition days, consisting of a diet low in grains, vegetables and fruits. This finding explains the athletes' low energy, but their high fat intake. A study investigating the nutrient intake of ultra endurance athletes showed that energy intake and antioxidant vitamins intakes were insufficient, and coincided with an inadequate consumption of fruits and vegetables ${ }^{[44]}$.

\section{Micronutrient intake:}

During long and strenuous aerobic exercise, adequate intake of antioxidant vitamins is essential to protect athletes against oxidative damage ${ }^{[46]}$. The key to maintaining an effective immune system is to avoid deficiencies of the nutrients that play an essential role in the proper immune function. An adequate intake of vitamins $\mathrm{A}, \mathrm{E}, \mathrm{B}_{6}, \mathrm{~B}_{12}$, iron and zinc is particularly important for the maintenance of immune function ${ }^{[47]}$. In the present study, mean dietary intakes for vitamins $\mathrm{B}_{12}, \mathrm{D}, \mathrm{E}$ and $\mathrm{K}$, biotin, folate, calcium, magnesium, potassium, iodine were below the RDA values, while female cross country skiers also exhibited inadequate intakes in iron and the men in manganese.

Similar dietary inadequacies were also reported by mountaineering skiers ${ }^{[13]}$. The intake of vitamins $A$, $\mathrm{B}_{1}, \mathrm{~B}_{2}, \mathrm{~B}_{6}$, and niacin is negatively related to the activity of LDH and alkaline phosphatase, whereas intake of iron, sodium and zinc were negatively correlated to the CK activity. All the above enzymes are related to cell damage ${ }^{[13]}$. The inadequacies recorded in several micronutrients in the present study can be partly compensated by the fact that some Greek skiers took supplements.

Finally, a skiing competition is usually followed by a visit to the ski-bar for reward drinks. Although alcohol intake is not censurable for adults, this habit does not help refueling after a sports event. In the present study, the alcohol consumption was low, but alcohol consumption after sports participation is a common problem ${ }^{[16]}$. Although the actual fluid consumption during training and competition was not measured in this study, most athletes consume drinks only when thirst appears in order to postpone urination [9]. This may imply that the skiers are chronically dehydrated before training. Toilets are usually far from the competition spot and the bulky equipment might lengthen the time needed to reach the toilets, and thus athletes tend to abstain from consuming fluids. In competition days, fluid intake is only needed in races longer than 15-20 km, since in such races athletes lose of $2-3 \%$ of body mass ${ }^{[9]}$.

We are aware of the limitations of the present study. For example, we did not measure hydration status of the athletes, and the estimates of physical activity and energy intake are self-reported. However, the methods used in the present investigations are well tried and tested, and were commonly used by the researchers in their everyday clinical practice and research activities. Therefore, we believe that, despite these limitations, the data collected are true and valid reflection of the dietary intake of the sample of skiers studied.

\section{CONCLUSION}

In the present study, female cross country skiers had higher body fat and lower lean body mass and body water compared to male cross country skiers. The two methods used for assessing body composition were highly correlated. Both male and female Greek crosscountry skiers had lower energy intake compared to their estimated energy expenditure and follow a diet inadequate in nutrient content. Specifically, the diet consumed was low in carbohydrates and several micronutrients. Improving macronutrient and micronutrient intakes could ensure adequate energy for performance and minimize fatigue and the risk of injuries. Nutritional counselling by dieticians and sports nutritionists is necessary to optimize athletic performance. In addition, studies regarding nutritional habits among cross-country skiers are limited. Further studies are therefore essential to establish specific dietary guidelines for cross-country skiing. 


\section{ACKNOWLEDGMENTS}

The present study was co-funded by "Archimedes 1", a research project funded by the EU and the Greek Ministry of Education.

\section{Conflict of interests: None}

\section{REFERENCES}

1. Rees D. Cross-country skiing: touring and competition ( $3^{\text {rd }}$ ed). Toronto: Copp C. Pitman. 1981.

2. Ekblom, B, Bergh U. Cross-country skiing. In Maughan RJ (ed). Nutrition in Sport. Oxford: Blackwell Science. 2000; pp: 656-62.

3. Mahood NV, Kenefick RW, Kertzer R, Quinn TJ. Physiological determinants of cross-country ski racing performance. Med Sci Sports Exerc 2001;33:1379-84.

4. Hoffman MD, Clifford PS. Physiological comparisons of cross country skiing techniques. Med Sci Sports Exerc 1992;24:841-8.

5. Clifford PS. Scientific basis of competitive cross - country skiing. Med Sci Sports Exerc 1992;4:1007-9.

6. Eisenman PA, Johnson SC, Bainbridge CN, Zupan MF. Applied physiology of cross-country skiing. Sports Med 1989;8:67-79.

7. Bergh U, Forsberg A. Influence of body mass on cross-country ski racing performance. Med Sci Sports Exerc 1992;24:1033-9.

8. International Ski Federation. The Role of Adequate Nutrition for Performance and Health for Female Cross-Country Skiers. Available at: http://www.fis-ski.com. Access date:

9. Burke LM, Cox GR, Culmmings NK, Desbrow B. Guidelines for daily carbohydrate intake: do athletes achieve them? Sports Med 2001;31:267-99.

10. American Dietetic Association, Dieticians of Canada, and the American College of Sports Medicine. Position of the American Dietetic Association, Dieticians of Canada, and the American College of Sports Medicine: Nutrition and athletic performance. J Am Diet Assoc 2009;109:509-27.

11. Zalcman I, Guarita HV, Juzwiak CR. Nutritional status of adventure racers. Nutrition 2007;23:404-11.

12. van Erp-Baart AMJ, Saris WHR, Binhkhorst RA et al. Nationwide survey on nutritional habits in elite athletes. Part I. Energy, Carbohydrate, protein and fat intake. Int J Sports Med 1989;10:S3-10.

13. Diaz E, Ruiz F, Hoyos I, et al. Cell damage, antioxidant status, and cortisol levels related to nutrition in ski mountaineering during a two-day race. J Sports Sci Med 2010;9:338-46.

14. Hassapidou NM, Manstrantoni A. Dietary intakes of elite female athletes in Greece. J Hum Nutr Diet 2001;14:391-6.

15. Papadopoulou SK, Papadopoulou SD, Gallos GK. Macro and Micro-nutrient Intake of Adolescent Greek Female Volleyball players. Int J Sport Nutr Exerc Metab 2002;12:73-80.

16. Doumtsios I, Grammatikopoulou MG, Tsigga M. Diet quality and anthropometry between different sailboarding styles. Nutr Diet 2010;67:31-6.

17. Papadopoulou SK, Papadopoulou SD. Nutritional status of team sport athletes according to body fat status. Nutr Food Sci 2010;40:6473.

18. Papadopoulou SK, Papadopoulou SD, Skoufas D, et al. Dietary intake differences between volleyball and handball women athletes of the Olympic national team. Medicina Sportiva 2008;4:983-9.

19. Heyward VH, Stolarczyk LM. Skinfold method. In: Applied Body Composition Assessment. Champaign, IL: Human Kinetics, 1996; Pp:21-43.

20. Jackson AS, Pollock ML. Generalized equations for predicting body density of men. Brit J Nutr 1978;40:487-504.

21. Jackson AS, Pollock ML, Ward A. Generalized equations for predicting body density of women. Med Sci Sport Exerc 1980;12:17582.

22. Siri WE. Body composition from fluid spaces and density: Analysis of methods. In: Brozek J, Heschel A (eds). Techniques for measuring body composition. Washington, DC: National Academy of Sciences, 1961; Pp:223-44.

23. Ainsworth BE, Haskell WI, Whitt MC et al. Compendium of Physical Activities: an update of activity codes and MET intensities. Med Sci Sports Exerc 2000;32 (9):S498-S516.

24. Mifflin MD, Jeor ST, Hill LA et al. A new predictive equation for resting energy expenditure in healthy individuals. Am J Clin Nutr 1990;51(2):241-7.

25. Crawford PB, Obarzanek E, Morrison J, Sabry ZI. Comparative advantage of 3-day food records over 24-hour recall and 5-day food frequency validated by observation of 9- and 10-year-old girls. J Am Diet Assoc 1994;94(6):626-30.

26. Institute of Medicine. Dietary Reference Intakes for Energy, Carbohydrates, Fiber, Fat, Protein, and Amino Acids (Macronutrients). Washington, DC: National Academy Press; 2003. 
27. U.S. Department of Agriculture. The Food Guide Pyramid. Available at: http://www.nal.usda.gov/fnic/Fpyr/pmap.htm. Access date: April 17, 2012.

28. Knechtle B, Duff B, Amtmann G, Kohler G. Cycling and running performance, not anthropometric factors are associated with race performance in a triple iron triathlon. Res Sports Med 2007;15:257-69.

29. Knechtle B, Schwanke M, Knechtle P, Kohler G. Decrease in body fat during an ultra-endurance triathlon is associated with race intensity. Br J Sports Med 2008;42:609-13.

30. Knechtle B, Kohler G. Influence of anthropometry on race performance in ultra edurance triathletes in the longest triathlon in North America. Int Sportmed J 2007;8:87-96.

31. Knechtle B, Knechtle P, Schulze I, Kohler G. Upper arm circumference is associated with race performance in ultra endurance athletes. Br J Sports Med 2008;42:295-9.

32. Knechtle B, Wirth A, Rosemann T. Is body fat a predictor variable for race performance in recreational female ironman triathletes? Medicina Sportiva 2011;15:6-12.

33. Fiskerstrand A, Seiler KS. Training and performance characteristics among Norwegian International rowers 1970-2001. Scand J Med Sci Sports 2004;14:303-10.

34. Wilmore JH. Body composition in sport and exercise: directions for future research. Med Sci Sports Exerc 1983;15:21-31.

35. Knechtle B, Wirth A, Knechtle P, Rosemann T. An ultra-cycling race leads to no decrease in skeletal muscle mass. Int J Sports Med 2009;30:163-7.

36. Papandreou D, Eystathiadis P, Bouzouki V, Hassapidou M. Dietary assessment, anthropometric measurements and nutritional status of Greek professional athletes. Nutr Food Sci 2007;37:338-44.

37. Hassapidou M. Dietary assessment of five male sports teams in Greece. Nutr Food Sci 2001;31:31-4.

38. Hassapidou MN, Grammatikopoulou MG, Liarigovinos T. Dietary intakes of Greek professional football players. Nutr Food Sci 2000; 30:191-3.

39. Suetta C, Kanstrup IL, Fogh-Andersen N. Haematological status in elite long-distance runners: influence of body composition. Clin Physiol 1996;16:563-74.

40. Hortobagyi T, Israel RG, Homard JA et al. Comparison of four methods to assess body composition in black and white athletes. Int $J$ Sport Nutr 1992;2:60-74.

41. Magkos F, Yannakoulia M. Methodology of dietary assessment in athletes: concepts and pitfalls. Curr Opin Clin Nutr Metab Care 2003;6(5):539-49.

42. Nogueira JAD, Da Costa THM. Nutritional status of endurance athletes: what is the available information? Archivos Latinoamericanos de Nutrición, versión impresa. ISSN 0004-0622. ALAN v.55 n.1 Caracas ene. 2005.

43. Loucks AB. Energy balance and body composition in sports and exercise. J Sport Sci 2004;22:1-14.

44. Lemon PW. Beyond the zone: protein needs of active individuals. $J$ Am Diet Assoc 2000;19:513S-21S.

45. Machefer G, Groussard C, Zouhal $\mathrm{H}$ et al. Nutritional and plasmatic antioxidant vitamin status of ultra endurance athletes. $J$ Am Coll Nutr 2007;26:311-6.

46. Maughan RJ. Role of micronutrients in sport and physical activity. Br Med Bull 1999;55:683-90.

47. Calder PC, Jackson AA. Undernutrition, infection and immune function. Nutr Res Rev 2000;13:3-29. 